\title{
Compression Moulding and Injection over moulding of porous PEEK components
}

\author{
A Siddiq $a,{ }^{1}$ and A.R. Kennedyc ${ }^{*}$ \\ a Faculty of Engineering, University of Nottingham, Nottingham, NG2 7JU \\ ${ }^{1}$ Present address, Institute for Innovation in Sustainable Engineering, University of Derby \\ c* corresponding author: Engineering Department, Lancaster University, Lancaster LA1 4YW, UK
}

\begin{abstract}
A simple and adaptable process for the production of porous PEEK has been demonstrated herein, which uses compression moulding to infiltrate molten PEEK into of a packed bed of salt beads. The process has the capacity to vary the pore size and porosity within the range suitable for materials to replace bone, but compressive testing showed the stiffness to be well below the target to match trabecular bone. This issue was addressed by creating a hybrid structure, integrating "pillars" of solid PEEK into the porous structure, by the injection overmoulding of compression moulded PEEK-salt inserts that contained drilled holes. Good bonding between the moulding and the insert was demonstrated and it was found that as little as $35 \mathrm{~mm}^{2}$ of support, in the form of PEEK "pillars" was required to achieve the target performance.
\end{abstract}

\section{Keywords}


PEEK, porous structure, injection moulding, compression testing

\subsection{Background}

Permanent, porous biomaterial structures have the ability to provide a transitional space between bone and a biomaterial substrate (which provides the main structural support). An appropriate level and geometry of porosity enables bone in-growth and hence enhanced integration between the bone and the biomaterial structure. Poly-ether-ether ketone (PEEK) has attracted wide interest as a material from which a porous medical device could be made [1]. The benefits of PEEK include; exceptional strength and stiffness for a thermoplastic polymer, excellent chemical resistance and bio-passive behaviour, X-ray translucence and excellent wear properties [2-8].

Although the service requirements for medical devices vary significantly, the design of an appropriate porous structure necessitates a balance between achieving sufficient strength to transfer load to the surrounding tissue and adequate (and appropriately sized) interconnecting pore spaces for tissue growth, substance transplantation, and vascularization [9-11]. Previous studies, and commercial porous metals, often aim to mimic the structural morphology of trabecular bone $[12,13]$, targeting porosities between 65 and $80 \%$ and mean pore diameters (or strut spacings) in the range of 400 to $800 \mu \mathrm{m}[1,14]$. In order to alleviate stress shielding, it has been proposed that the elastic modulus of the porous structure should also match that of human trabecular bone, which can vary in the range from 300 to $3200 \mathrm{MPa}[12,13]$.

The creation of porous structures using sacrificial space- holders, which can be dissolved away after processing, is very popular as it offers the ability to control the pore fraction, size and shape. The routes to achieving this vary, and in the context of biomaterials are overviewed in $[15,16]$. Previous work by this group [17] has shown that highly porous PEEK structures can be produced by the integration, by tapping, of fine PEEK into a pre-existing network of $\mathrm{NaCl}$ 
(salt) beads, followed by compaction and "sintering" and removal of the salt by dissolution in water. By pre-establishing the contacts between the salt beads, before addition of the PEEK powder, structures with; improved repeatability and homogeneity of density, more uniform pore and strut sizes, an improved and predictable level of connectivity, faster salt removal rates and lower levels of residual salt were produced, compared to other processing methods [1825]. The stiffness (39 MPa) and the compressive yield strength (1.2 MPa) of porous PEEK containing $84 \%$ porosity were, however, still some considerable margin below the lower limits (300 MPa and $2 \mathrm{MPa}$, respectively) for trabecular bone $[12,13]$. In much the same way as has been observed in Al systems, [26-28] an improvement in mechanical properties, in particular the stiffness, would be expected if the cell walls did not contain microporosity.

In order to protect porous PEEK structures, of the type produced in [17], from yielding under inter-lumbar loads (which typically range from 1000-3000 N, depending upon activity [2932]), up to $2500 \mathrm{~mm}^{2}$ of load bearing area would be required. It is, therefore, more practical to integrate these porous elements into hybrid structures where they can be protected from damage. Key to the success of producing a hybrid device is achieving strong bonding between the porous part and the body of the device. In medical devices, this may also need to be achieved without the use of adhesives. Integration of the porous part into an injection moulding of the device offers an attractive solution, but consideration needs to be made to ensure that the moulding forces do not deform or fracture the porous part and that the porosity is not filled during the over-moulding process.

This study aims to demonstrate a novel infiltration route, using molten PEEK and salt beads, for the production of porous parts with homogenous structures and improved properties compared to equivalents made from powders. It further aims to demonstrate a new approach to integrating porous parts into PEEK structures, adapting them, and the injection moulding 
process used, to achieve good integration between the two and an enhancement in the capacity for the porous insert to resist plastic deformation.

\subsection{Experimental Methodology}

\subsubsection{Compression moulding - infiltration}

Commercially available salt beads used in water softeners (Hydrosoft, typically $>99.9 \% \mathrm{NaCl}$ ) were used, sieved to achieve size ranges between 0.5-1.0, 1.0-1.4 and 2.0-2.4 mm. A composite PEEK-salt part was produced by a hybrid compression moulding-infiltration process, by forcing molten PEEK into a packed bed of salt beads [33]. Figure 1 shows a schematic of the process, which utilises a steel mould (with male and female parts) and a heated press with the capability to control the applied load and temperature. Figure 2 shows the morphology of the largest and smallest beads used. Although sieved from the same source, the smaller beads are more angular and are mostly composed of fractured larger beads.

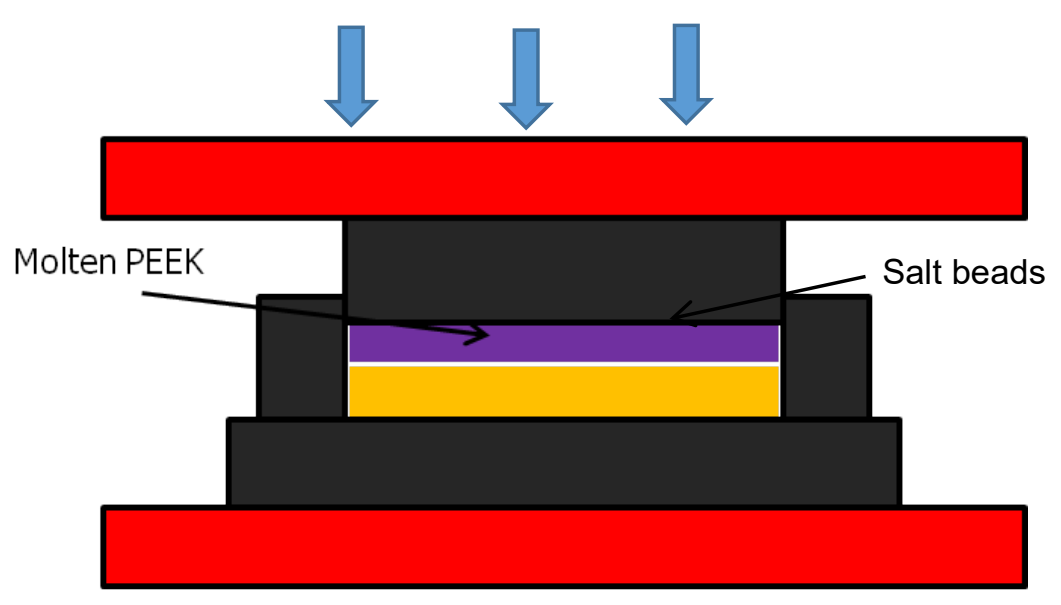

Figure 1 Schematic of the compression moulding - infiltration process 


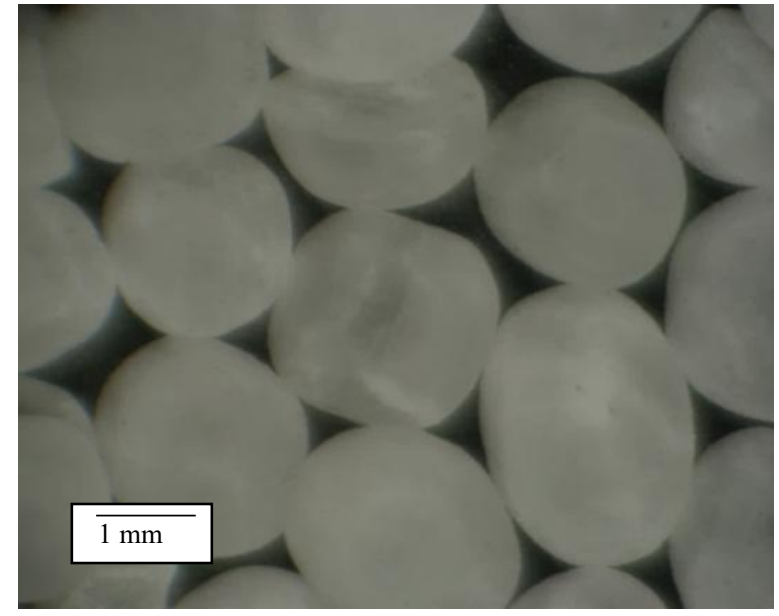

a)

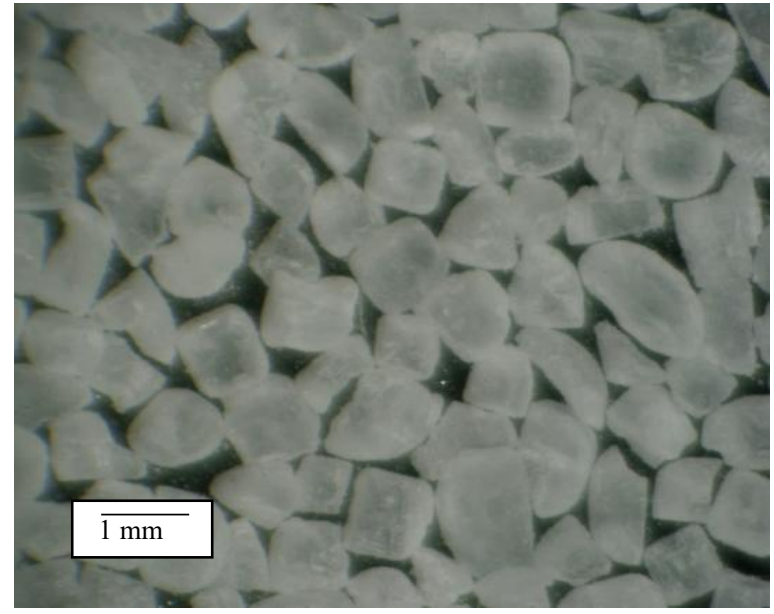

b)

Figure 2 Loose-packed salt beads with size ranges a) 2.0-2.4 $\mathrm{mm}$ and b) 0.5-1.0 $\mathrm{mm}$.

A predetermined mass of salt beads (based on the thickness of part required) was poured into the cavity of the steel mould (150 $\mathrm{mm}$ in diameter and $28 \mathrm{~mm}$ high) which had been spray coated with boron nitride to assist with de-moulding at the end of the process. The beads were then levelled using a manual device to help achieve uniform spreading in the tooling. In the case of the $0.5-1.0 \mathrm{~mm}$ diameter beads, the top platen was inserted into the cavity and loads ranging between 100 and $600 \mathrm{kN}$ (pressures between 5.5 and $33 \mathrm{MPa}$ ) were applied to increase their packing density, in an effort to vary the porosity in the resulting parts. For the other 2 particle sizes, pre-compaction was only performed using a load of $100 \mathrm{kN}$.

With the tooling open, the requisite mass of PEEK powder (150PF grade, $54 \mu \mathrm{m}$ mean diameter [17], supplied by Victrex, UK) was then poured onto the bed of salt beads and spread evenly over the surface. For a salt mass of $200 \mathrm{~g}$, which for the pre-compaction setup produces discs in the range of 6-8 mm thick, $45 \mathrm{~g}$ of PEEK was used. In all cases, the mould was then closed and placed into a press and a $100 \mathrm{kN}$ force was applied and maintained throughout the entire infiltration process. The press platens were heated to $420 \pm 5^{\circ} \mathrm{C}$, heating the tooling via conduction, melting the PEEK powder in approximately 2 hours. 
After the PEEK melted and was able to flow, the upper platen was automatically displaced to maintain the same pressure. After a 30 min hold at temperature, the platens were cooled whilst the pressure was maintained. After cooling to room temperature, the tooling was removed from the press, opened and the part removed. Parts for evaluation were extracted by manual sawing, or by conventional machining methods, with the salt still in place.

After removal of any excess PEEK from the upper surface (by either manual or mechanical grinding), the salt was then removed from the discs by immersion in a water bath held at $40^{\circ} \mathrm{C}$. To be confident that near complete salt removal had been achieved, the electrical conductivity of the water in the bath containing the samples was measured. The conductivity rises very strongly with salt content and a levelling out with time is a good indication that the process is nearly complete [34]. For final verification, porous samples were re-immersed in deionised water and if no appreciable change in conductivity was detected, it was assumed that all the salt that could be removed (i.e. that which is not fully encapsulated by PEEK), had been removed.

\subsubsection{Injection over-moulding}

$22 \mathrm{~mm}$ diameter discs were removed from $6 \mathrm{~mm}$ thick compression mouldings made using 0.5 $1.0 \mathrm{~mm}$ salt beads, with relative densities in the range of $0.20-0.22$, using a core drill. $3 \mathrm{~mm}$ and $5 \mathrm{~mm}$ diameter holes were drilled through the face of these samples, in order to create passages for the flow of PEEK during the moulding process, and "pillars" to shield the porous PEEK when loaded. Examples of drilled $22 \mathrm{~mm}$ diameter inserts, with the salt still intact, are shown in Figure 3. To improve adhesion between the injection moulded PEEK and the insert, salt was removed from the surfaces of the inserts by brief (circa 2 min) insertion into a water bath held at $40^{\circ} \mathrm{C}$. Trials showed that these conditions were sufficient to remove salt to a depth of at least one pore diameter. 


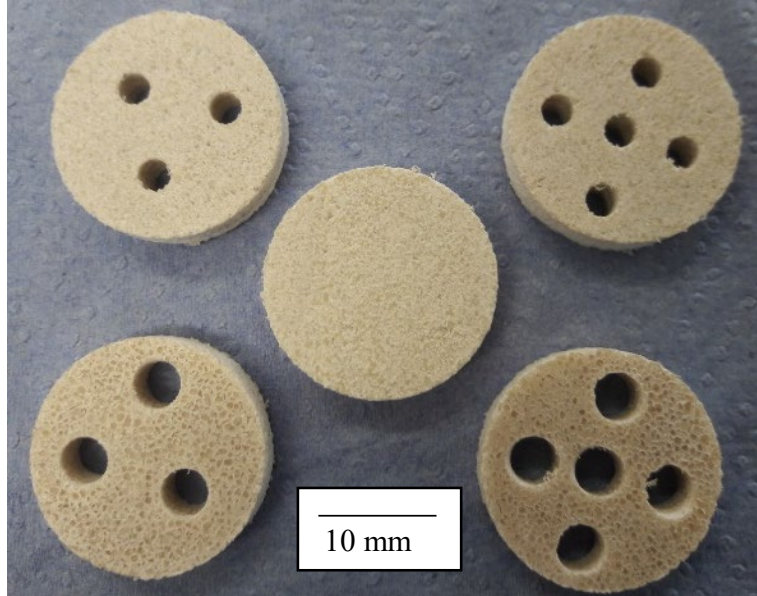

a)

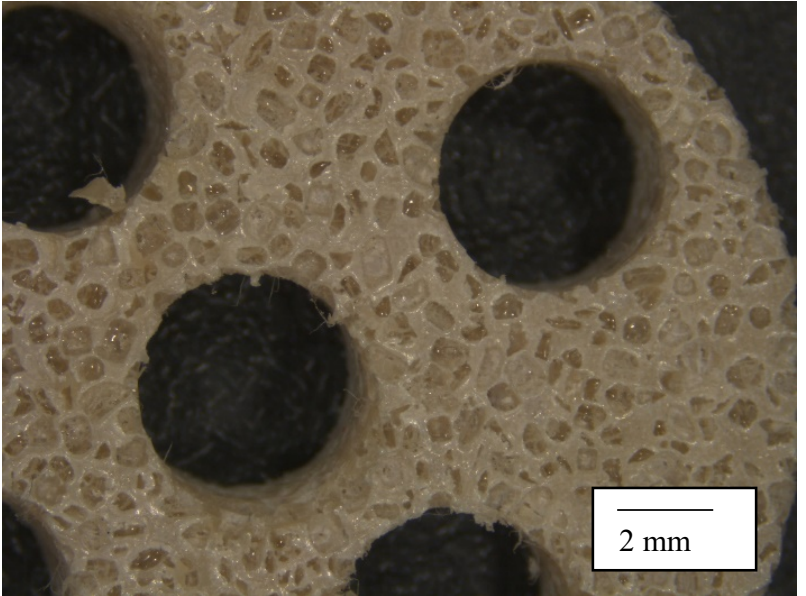

b)

Figure $322 \mathrm{~mm}$ diameter PEEK - salt composite inserts (salt size 0.5-1.0 mm) with a) 3 and $5 \mathrm{~mm}$ diameter and b) $5 \mathrm{~mm}$ diameter drilled holes

Injection over-moulding was performed using an Arburg injection moulding machine, injecting PEEK (450G grade, supplied by Victrex, UK) at a temperature of $375^{\circ} \mathrm{C}$ and injection pressure of $5 \mathrm{MPa}$, into a mould heated to $150{ }^{\circ} \mathrm{C}$. The mould cavity was originally $52 \times 52 \times 10.5 \mathrm{~mm}$ and was designed to make colour test plaques. It was modified using a close-fitting tool steel insert, $5.2 \mathrm{~mm}$ thick, with a $22 \mathrm{~mm}$ diameter, $2 \mathrm{~mm}$ deep hole in the centre, placed on the back face of the mould cavity, in order to create a fixture for PEEK-salt composite inserts. The depth of the hole to locate the insert meant that it protruded into the moulding by $4 \mathrm{~mm}$ and was encapsulated by a $1.3 \mathrm{~mm}$ thick layer of PEEK below it. Inserts were preheated to $150{ }^{\circ} \mathrm{C}$ in an oven and manually transferred to the mould cavity prior to mould closure and injection. The mould cavity and inserts are shown schematically in Figure 4. 

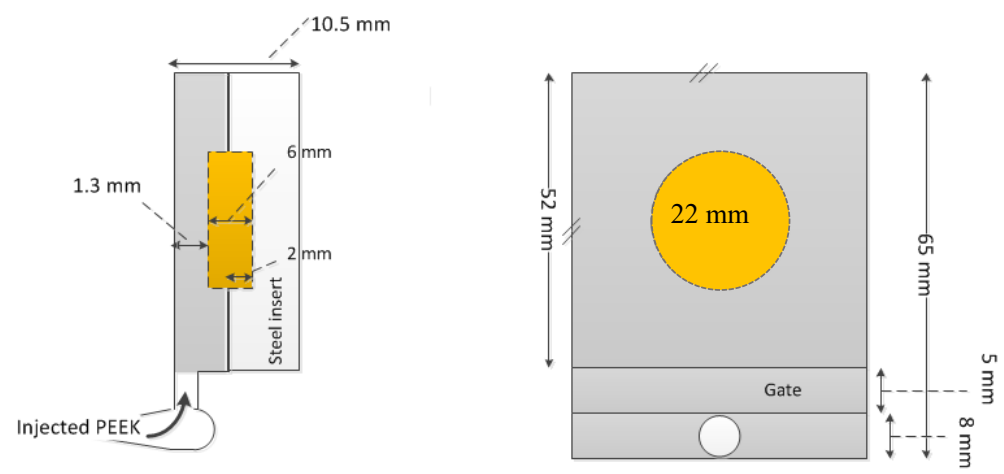

Figure 4 Schematic illustration of the mould cavity and moulding (mid-shading) including the PEEK - salt insert.

\subsubsection{Mechanical testing and characterisation}

Compressive mechanical testing was performed on porous samples using an Instron Universal Testing machine, compressing samples that were $22 \mathrm{~mm}$ in diameter and $6 \mathrm{~mm}$ in height. Samples were deformed at a rate of $0.6 \mathrm{~mm} \mathrm{~min}^{-1}$. In order to determine the stiffness, twin extensometers were used to accurately measure the compressive strain during 4 unloading and reloading cycles, after initial loading to approximately $75 \%$ of the compressive yield point. The yield stress was determined from the stress corresponding to $1 \%$ plastic strain.

Injection over-moulded coupons were prepared for mechanical testing by grinding, to ensure parallel top and bottom surfaces, removing less than $0.5 \mathrm{~mm}$ from the top of the insert. The salt was then removed by immersion in water and the samples were dried. Compressive testing was conducted in a similar way to the conventional porous samples, using a small cylindrical disc on top of the insert to ensure uniform loading. The testing configuration is shown schematically in Figure 5. A minimum of 4 samples per type were tested. 


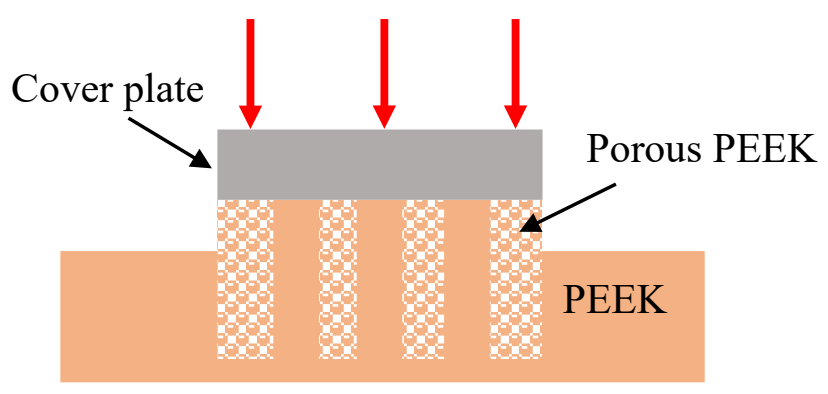

Figure 5 Schematic illustration of the mechanical testing setup for over-moulded porous PEEK components (not to scale).

The density of porous samples was measured from the dimensions and the mass, using a 3 figure balance and digital callipers. Their structure was examined using optical and scanning electron microscopy (SEM). Sectioned PEEK scaffolds were sputter coated with platinum prior to examination by SEM.

\subsection{Results and discussion}

\subsubsection{Infiltration}

All the samples were infiltrated successfully under the specified processing conditions. The tooling does not provide a gas-tight seal at the bottom of the mould and thus air within the preform is not compressed, thereby avoiding the creation of a back-pressure that would resist infiltration. An underside view of a typical moulding (with the $0.5-1.0 \mathrm{~mm}$ salt beads still in place) is shown in Figure 6a and a porous PEEK sample, after salt removal, is shown in Figure 6b. Owing to the slight non-parallelism of the press, the discs produced were not completely flat, varying by a maximum of $\pm 5 \%$ from the mean thickness. Whilst this did not result in dry (non-infiltrated) spots, excess PEEK was observed in patches on the top surface. It is also 
worth noting that in preliminary trials, higher pre-compression loads $(>800 \mathrm{kN})$ resulted in high density salt bead compacts that could not be infiltrated to produce a continuous structure, owing to the absence of a fully interconnected void structure.

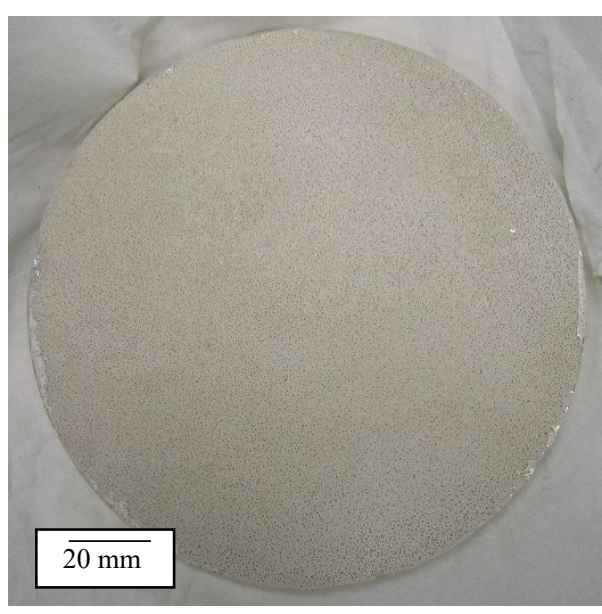

a)

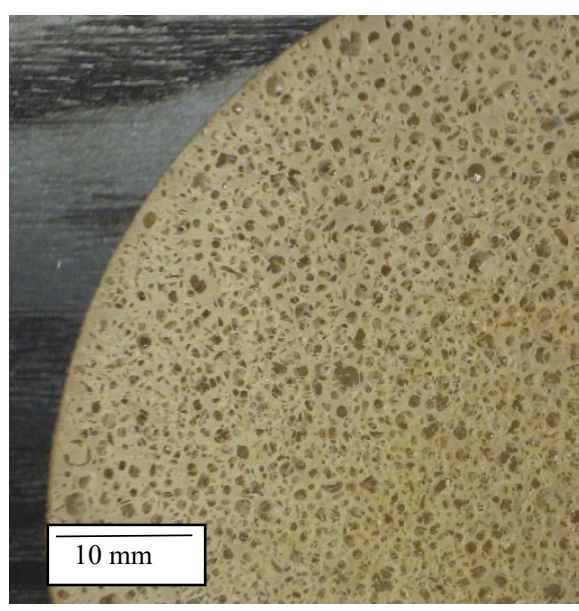

b)

Figure 6 Images showing a) a demoulded PEEK - salt “composite” and b) a machined disc after salt removal (both with $0.5-1.0 \mathrm{~mm}$ beads)

The capillary radius, which relates to the size of channel that can be infiltrated for a given liquid, at a given pressure, is very low for molten polymers owing to their low surface tension. An estimate for the capillary radius in the PEEK-salt system (based on the Young-Laplace equation - an example for the use of which is given in [35]) is less than $0.01 \mu \mathrm{m}$ at a pressure of 5.5 MPa. By considering that molten $\mathrm{Al}$ (with a surface tension at least an order of magnitude higher) can infiltrate packed beds of similarly sized salt beads at pressure differences less than 0.1 MPa [35], the pressure applied is well in excess of that needed for infiltration. 
Models such as those by Mortensen [36] can be used to estimate the time taken to infiltrate a packed bed of known permeability. Given the much higher viscosity of molten polymers, it is expected that infiltration would be much slower than for the corresponding process with a molten metal. On the basis of a constant pressure differential of magnitude corresponding to the full infiltration pressure, and a bed permeability calculated based on the smallest bead size and highest packing fraction [37], the model estimates infiltration of a $7 \mathrm{~mm}$ thick bed to take less than 10 seconds. Observations of the movement of the press during processing support relatively rapid infiltration, with complete displacement of the top platen (post melting of the PEEK) lasting a period of no more than one minute. If, as is commonly observed and modelled, a parabolic dependence of flow distance on time and pressure applies, infiltration times will increase significantly for thicker samples.

Porous structures with porosities in the approximate range of $75-85 \%$ were produced, varied by the pre-compaction pressures adopted. Figure 7 shows how the relative density (or solid fraction) decreases, and hence the porosity increases, in roughly a linear manner as the precompaction pressure, applied to $0.5-1.0 \mathrm{~mm}$ beads, increases. This behaviour is to be expected as higher pressures will lead to higher bead packing fractions and reduced volumes for polymer infiltration. The error bars presented in this figure reflect the scatter in density for a minimum of 6 samples taken at different positions within a single infiltrated disc. This reasonably broad scatter is a result of the non-parallelism of the press, as was highlighted earlier, which creates local variations in bead compaction density. 


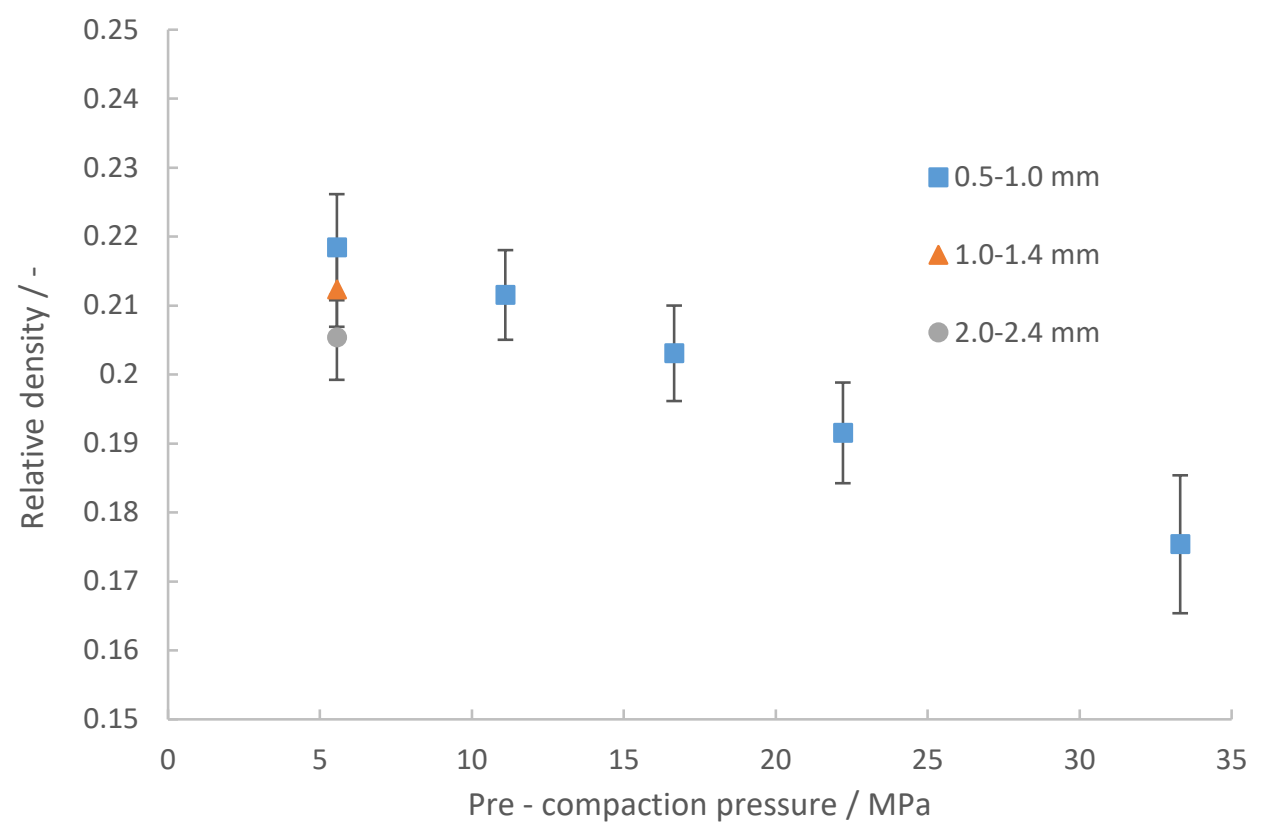

Figure 7 Average relative densities (and scatter) for porous samples taken from discs produced with different bead sizes, at different pre-compaction pressures

Figure 8 shows typical porous structures for samples made with the largest and smallest beads. Unlike for beads used in [17], which were porous and deformable, the pore structures closely replicate those of the rigid beads used in this study, in terms of size and shape. An important factor that controls the connectivity of the pore structure is the morphology and packing structure for the salt beads. Figure 2 indicates that for the largest beads, their slight deviation from sphericity enables them to pack more densely, to a tapped packing fraction of 0.69 (compared with a maximum of 0.64 for monosized spheres). This increases the number of contacts between each bead (their coordination number) and the inter-bead contact area. After exposure to molten PEEK at high pressure, all but the contact areas between the beads are infiltrated. This lack of penetration creates windows between the pores that give the structure its interconnectivity. The high degree of connectivity for the porous PEEK structure made with large, near-spherical beads is evident in Figures $8 \mathrm{a}$ and $8 \mathrm{~b}$, where it is estimated that, on 
average, there are $8-10$ windows per pore, with diameters between 500 and $800 \mu \mathrm{m}$, consistent with structures made using similar beads in [38].

In Figure 8c, pores containing filigree structures are observed. This is evidence that PEEK can infiltrate very small, micron-sized, cracks which form as particles are fractured as pressure is applied during the pre-compaction stage. Although present in low fractions, as was remarked for similar observations in the $\mathrm{Al}$ system in $[27,28]$, this material is unlikely to make an effective contribution to the stiffness of the structure and is undesirable from a structural perspective. Although Figure 8c presents an example for 2.0-2.4 mm beads, filigree structures were also observed in porous materials made with smaller beads. These structures only tend to be observed at higher pre-compaction pressures, since many of the small beads (shown in Figure 2) are formed as a result of fracturing larger beads and are hence less likely to contain defects which would enable them to fracture at lower pressures.

Figure $8 \mathrm{~d}$ shows a typical structure for porous samples made with the smallest beads $(0.5-1.0$ $\mathrm{mm}$ ). A larger fraction of non-spherical pores is observed, reflecting the morphology of the beads. Less efficient packing of these angular beads (which tap to a packing fraction of 0.61 ), means the coordination number is a little lower, resulting in typically 6-8 windows per pore. As a result of their reduced size and more angular shape, inter-particle friction increases and lower packing fractions and hence lower porosities are produced for the same pre-compaction loads. Figure 7 reflects this, showing that the solid fraction is higher than for larger salt bead sizes. Since the size of the contact areas decreases for smaller and angular beads, windows connecting the pores are now typically in the range of 100-300 $\mu \mathrm{m}$. 

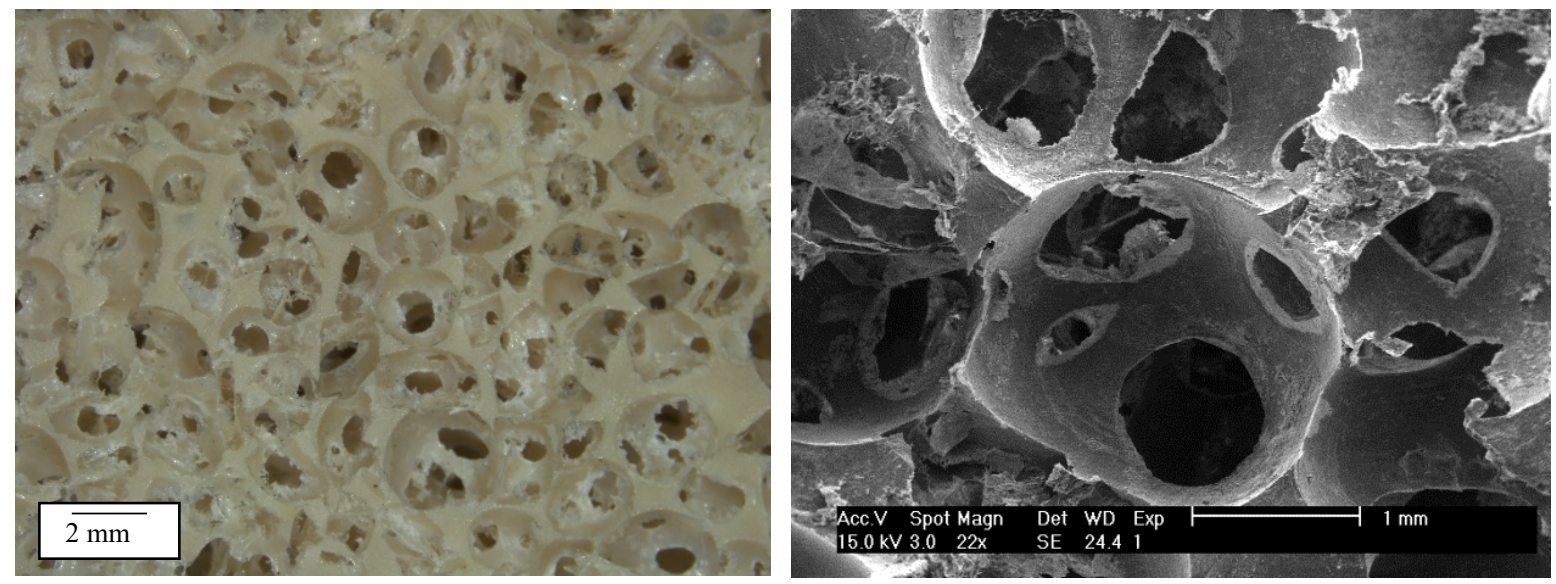

a)

b)
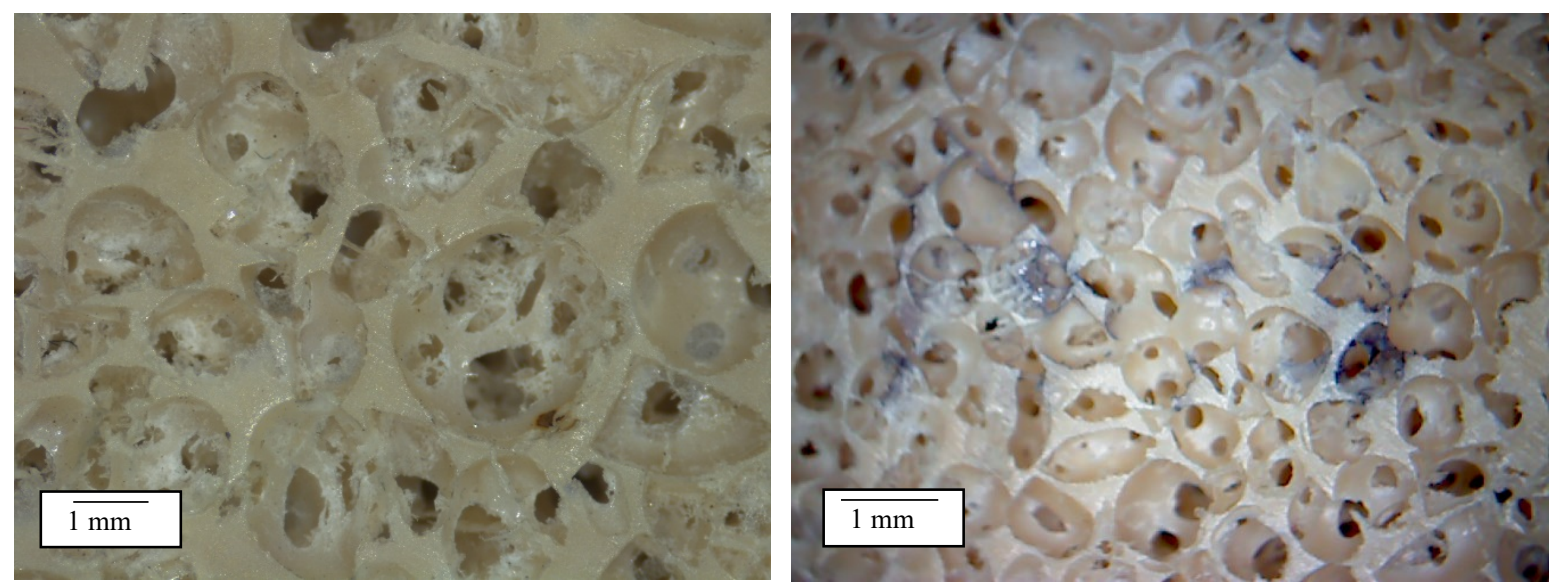

c)

d)

Figure 8 Optical microscope and SEM (b) images of porous PEEK structures made from a-c)

2.0-2.4 mm (relative density, 0.21) and d) 0.5-1.0 mm beads (relative density, 0.22).

Figure 9 shows a typical compressive stress - strain curve for a porous PEEK sample, in this case with a relative density (or PEEK fraction) of 0.20 . It shows typical features for compression of a porous structure, an initial elastic region, followed by yielding, a levelling of the stress with strain and finally a significant increase in load with strain above roughly 0.4 . The inset more clearly shows the behaviour at low strains over the 4 stiffness measurement cycles. As identified and remarked in [39] the first cycle shows a lower stiffness than the repeats (approximately 25\% lower), a discrepancy which is believed to be a result of micro 
plasticity (yielding of some of the struts) at stresses below the macroscopic plateau stress [40], and then a high level of reproducibility for the repeat cycles (less than $2 \%$ difference over all the cycles). Whilst measuring the gradient from the second loading cycle is an established method for determining the stiffness, this will not adequately define the in-service performance if a device is made and not pre-loaded before implantation. In addition to defining and following a robust testing protocol, measuring and eliminating the effects of machine compliance upon, in particular, stiffness measurements, is very important. Owing to the relatively low loads applied to the porous polymers in this study $(<4 \mathrm{kN})$ the difference between displacements measured by the LVDTs and the machine crosshead are very small (less than $0.5 \%$ ) and the error is small compared to those (40\%) for much stronger and stiffer porous Ti structures [39].

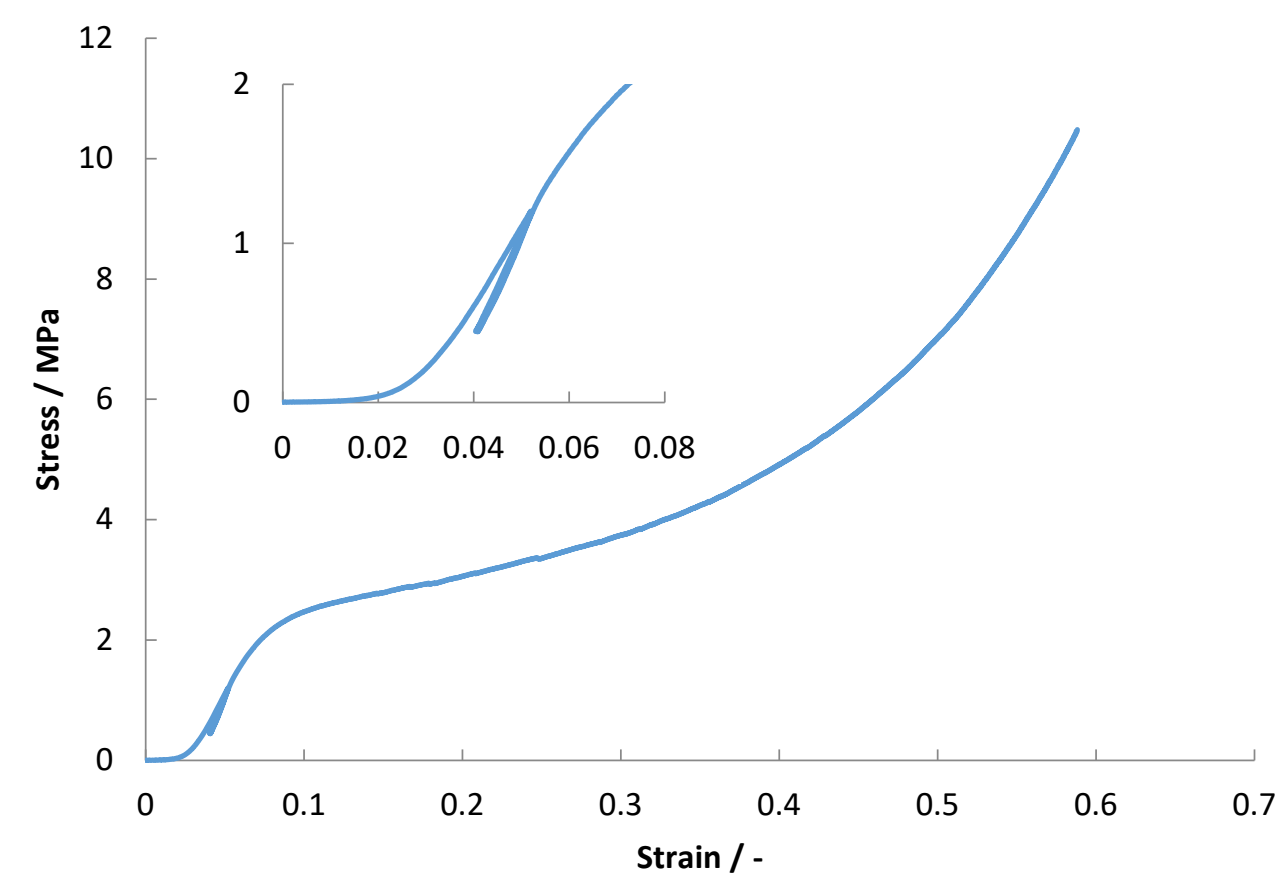

Figure 9 Typical compressive stress - strain curve for a porous PEEK sample with a relative density of 0.20 (detail of low strain behaviour is inset) 
Figures 10 and 11 show the stiffness and yield strength for porous samples, as a function of their relative density and are compared with data for samples from [17] made by sintering of tapped structures. Data for the stiffness are an average of the 4 cycles. The standard deviation for these cycles and the error in the measurement of the yield strength were both less than $2 \%$ and, for clarity, the error bars were omitted from Figures 10 and 11. Data points for 0.5-1.0 $\mathrm{mm}$ pore sizes clustered at low relative density (high porosity) are for samples produced at high pre-compaction loads and vice versa. It can be seen that data for samples with different pore sizes fit along the trend curve for the $0.5-1.0 \mathrm{~mm}$ pores, reaffirming the predominance of porosity over pore size in influencing the compressive response [41-43]. The stiffness and yield strength for PEEK, in compression, [44] are approximately 3.7 GPa and $125 \mathrm{MPa}$ and, as expected, considerable reductions in these values are observed for highly porous samples. Both these properties vary with relative density according to power laws [45], with exponents calculated to be 2.1 and 1.7 for stiffness and strength respectively (for both the $0.5-1.0 \mathrm{~mm}$ pores and for the whole data set). Values lower than those in [17] for sintered powder structures with micro porosity in the cell walls $(3.1$ and 4.2$)$ indicate that infiltration creates more structurally efficient materials with solid, non-porous cell walls, in spite of the efficiency being lower than optimum for those samples with high porosity, that contain filigree features within the pores. 


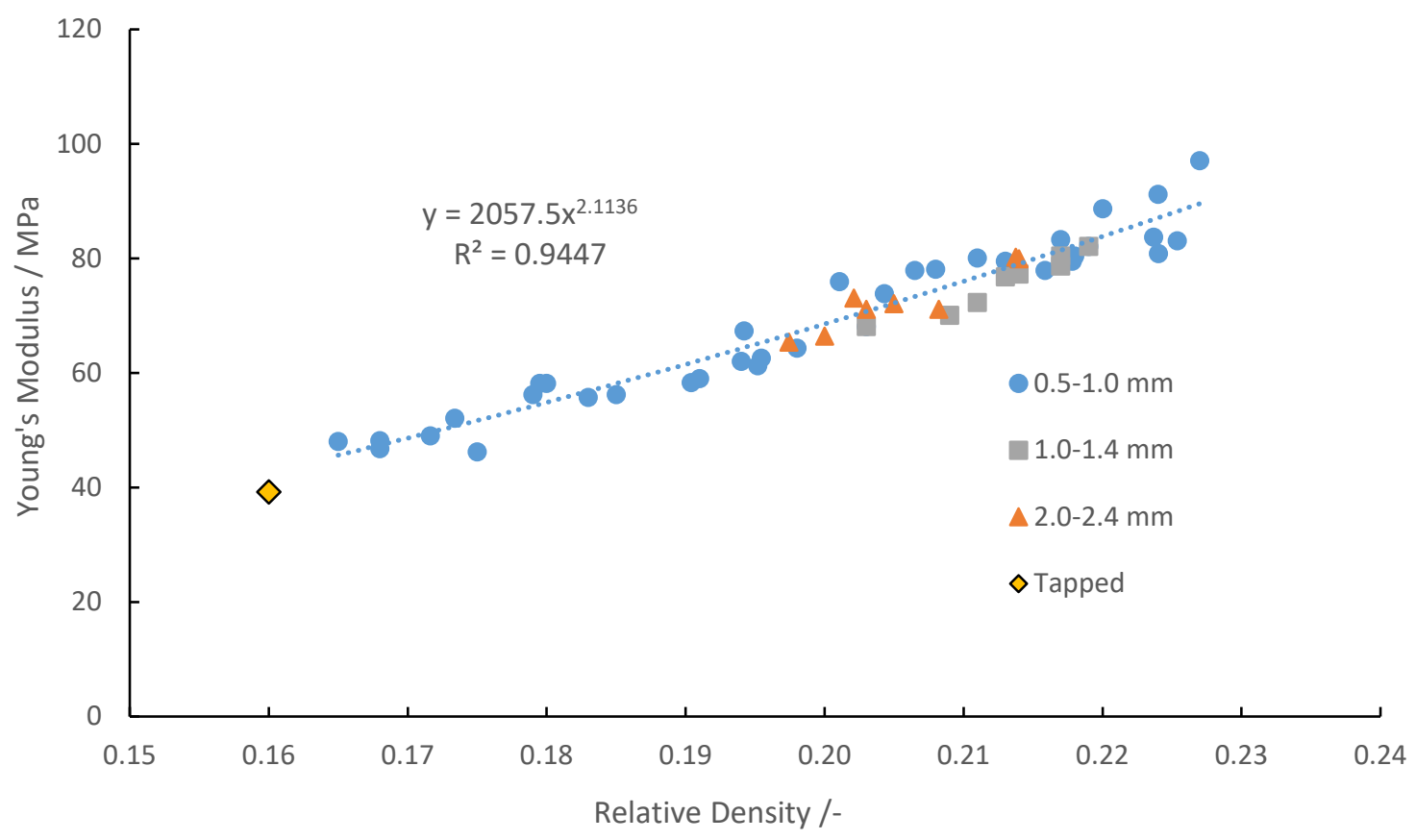

Figure 10 Stiffness - relative density plot for porous PEEK samples

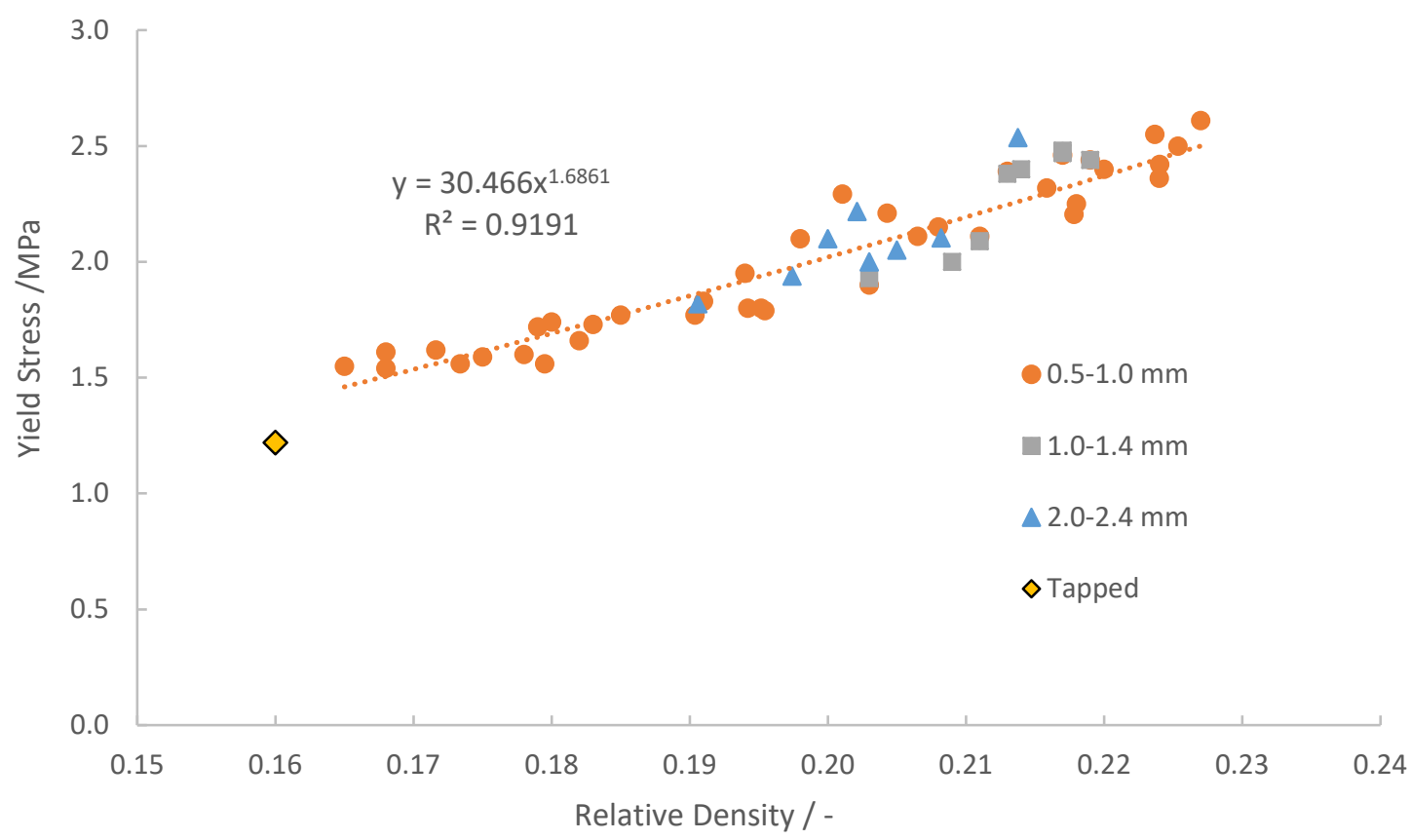


Figure 11 Compressive yield stress - relative density plot for porous PEEK samples

The process used has many advantages but could be improved. As currently presented, it lends itself to the production of relatively thin $(<15 \mathrm{~mm}$ thick) plates in large diameters, from which multiple smaller samples, of the scale typically used for medical devices, might be extracted. There is no reason why the tooling cannot be adapted to make thicker parts or larger, more complex shapes as per conventional compression moulding. Infiltration times will increase, but heating rates and holding times could be optimised to improve productivity. Improvement in the tooling design could ensure the production of flat samples, improving the homogeneity of bead packing density and thus porosity, offering a robust and reproducible process.

The compression moulding - infiltration process is able to produce samples that fall within the broad range of pore sizes and connectivities desirable for medical devices that aim to encourage bone in-growth and, by pre-compaction of the salt bead bed, is able to achieve pore contents in the region of $75-85 \%$. The uniformity, porosity and connectivity in finer porous structures could be further improved by increasing the sphericity of the $0.5-1.0 \mathrm{~mm}$ beads. Although the mechanical performance is enhanced, compared with similar structures derived from a powder route [17], and is consistent with similar structures in [9, 43], the compressive yield stress $(2.0$ $\pm 0.1 \mathrm{MPa})$ is at the bottom of the range for trabecular bone, and the stiffness $(69 \pm 1 \mathrm{MPa})$ is a considerable margin below the lower limit $(300 \mathrm{MPa}[12,13])$.

Extrapolations of the data in Figures 10 and 11 indicate that the stiffness and yield strength could be increased to approximately 280 and $6 \mathrm{MPa}$ respectively, at the very minimum of the 
porosity achievable for the smallest salt beads. Unfortunately, the infiltration pressure (the minimum that can be applied by the press used) affects sufficient compaction of the salt beads during the heat-up stage that porosities lower than $75 \%$ were unachievable using this setup. Irrespective of processing practicalities, and any implications to the reduction in connectivity arising from decreased porosity, achieving the target trabecular bone stiffness appears to be beyond the capability of PEEK structures of this type.

\subsubsection{Injection over-moulding}

For all the inserts, the injected PEEK flowed through all the pre-drilled holes and into the surface pores created by salt removal, prior to it freezing. Incomplete infiltration of the surface porosity, as a result of premature freezing, was only observed during preliminary tests conducted at insert preheating temperatures below $100{ }^{\circ} \mathrm{C}$.

Fully infiltrated inserts were securely integrated into the mouldings. Without dissolution of salt from the surface of the insert, adhesion between the moulding and the insert was weak and led to their separation after ejection from the mould. Attempts were also made to infiltrate saltonly preforms, made by compaction, in a single step in the injection moulder. Complete infiltration could not be achieved before freezing of the injected polymer, using any pressure or temperature within the processing "window" for injection moulding of PEEK.

Figure 12a shows an over-moulded insert, where the pillars created by filling drilled holes with different diameters, are marked. Figure $12 \mathrm{~b}$ shows the ingress of PEEK into the empty pores around the periphery of a sectioned insert (interface shown as a dashed line) and its flow into neighbouring pores through the windows (also marked in this figure). In this sample, the 
remaining salt has also been removed. The injection pressure is very similar in magnitude to that for compression moulding in this study and it is not surprising that PEEK is able to flow through pores and connecting windows that are very much larger than the estimated capillary radius. Dissolution of the salt from the outer layer of the insert, and the penetration of the injection moulded PEEK therein, is vital to provide a mechanical key and good adhesion between the two components. Leaving the majority of the salt in the insert during moulding ensures that the injected PEEK does not eliminate all the porosity. Despite the nominal moulding pressure exceeding the yield strength of a porous PEEK insert, minimal damage was observed to exposed pores on the surface of the inserts during over-moulding. Compression testing of surface porous PEEK has shown that thin layers of surface porosity, as is the case for the insert, show a much greater resistance to plastic deformation than thicker porous layers or bulk porous samples [43], supporting these observations.

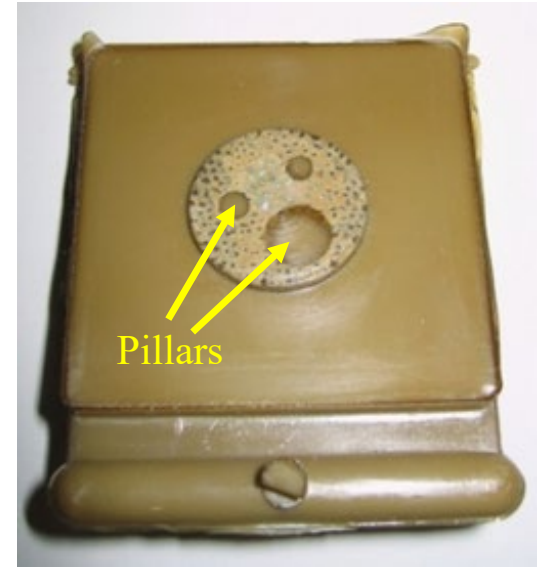

a)

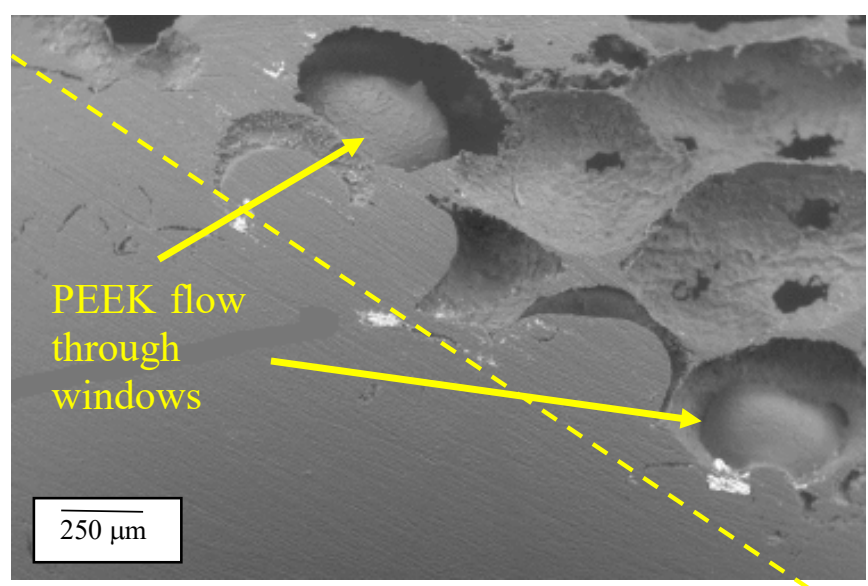

b)

Figure 12 Images showing a) an over-moulded insert and b) injected PEEK permeating the porous insert (prior surface of the insert is indicated by the dashed line).

Typical force-displacement curves for over-moulded samples, with and without "pillars" of PEEK, are presented in Figure 13. Images for porous sections containing $3 \mathrm{x}$ and $5 \mathrm{x} 3 \mathrm{~mm}$ diameter pillars are inset in this figure. The mechanical response, limited to small 
displacements, given the $2 \mathrm{~mm}$ (maximum) protrusion from the moulding, shows elastic, followed by plastic deformation behaviour. An increase in load-bearing capacity, before yielding, is observed as the total cross sectional area of the pillars supporting the load increases. The introduction of $5 \mathrm{x} 3 \mathrm{~mm}$ diameter pillars is sufficient to ensure that a $3000 \mathrm{~N}$ lumbar load would be supported, with some margin, without causing macroscopic plastic deformation.

Table 1 presents the stiffness and yield stress for the deforming hybrid structure, calculated using the nominal cross sectional area and thickness for the insert, after removing the estimated elastic displacement for the support below the insert. Bracketed figures are the stiffness and yield strengths estimated using a rule of mixtures approximation (using data from [44] and measured in this work). The table shows that the porous sample, without supports, exhibits a stiffness and compressive strength consistent with that measured earlier in this study, albeit with a higher scatter, giving confidence to the measurement process. The introduction of $5 \times 3$ mm diameter PEEK "pillars" increases the stiffness to $386 \mathrm{MPa}$ and the compressive yield strength to 13.0 MPa, exceeding the lower limits for trabecular bone [12, 13].

Measurements tend to be below, but agree fairly well with, the estimates based on the rule of mixtures. The assumption of equal strains in the two components and the application of the rule of mixtures is not unreasonable. The matrix stress estimated by this approach, at global yield, is very close to the average yield stress for the porous material. The test setup is, however, unconventional given the limitations imposed by the moulding geometry. Although the lower two thirds of the porous sample are constrained by the surrounding PEEK, the small displacements imposed (less than one pore diameter) are likely to be localised in the uppermost (unconstrained) layers of pores. Whilst a numerical modelling approach might help understand the deformation behaviour, deviation from the experimental measurements herein are still expected owing to imprecise and non-uniform hole diameters and uncertainty in materials properties. The approximation presented, however, appears to be of value for aiding the design 
of appropriate geometries and numbers of "pillars" for a particular application and the forces that go with it.

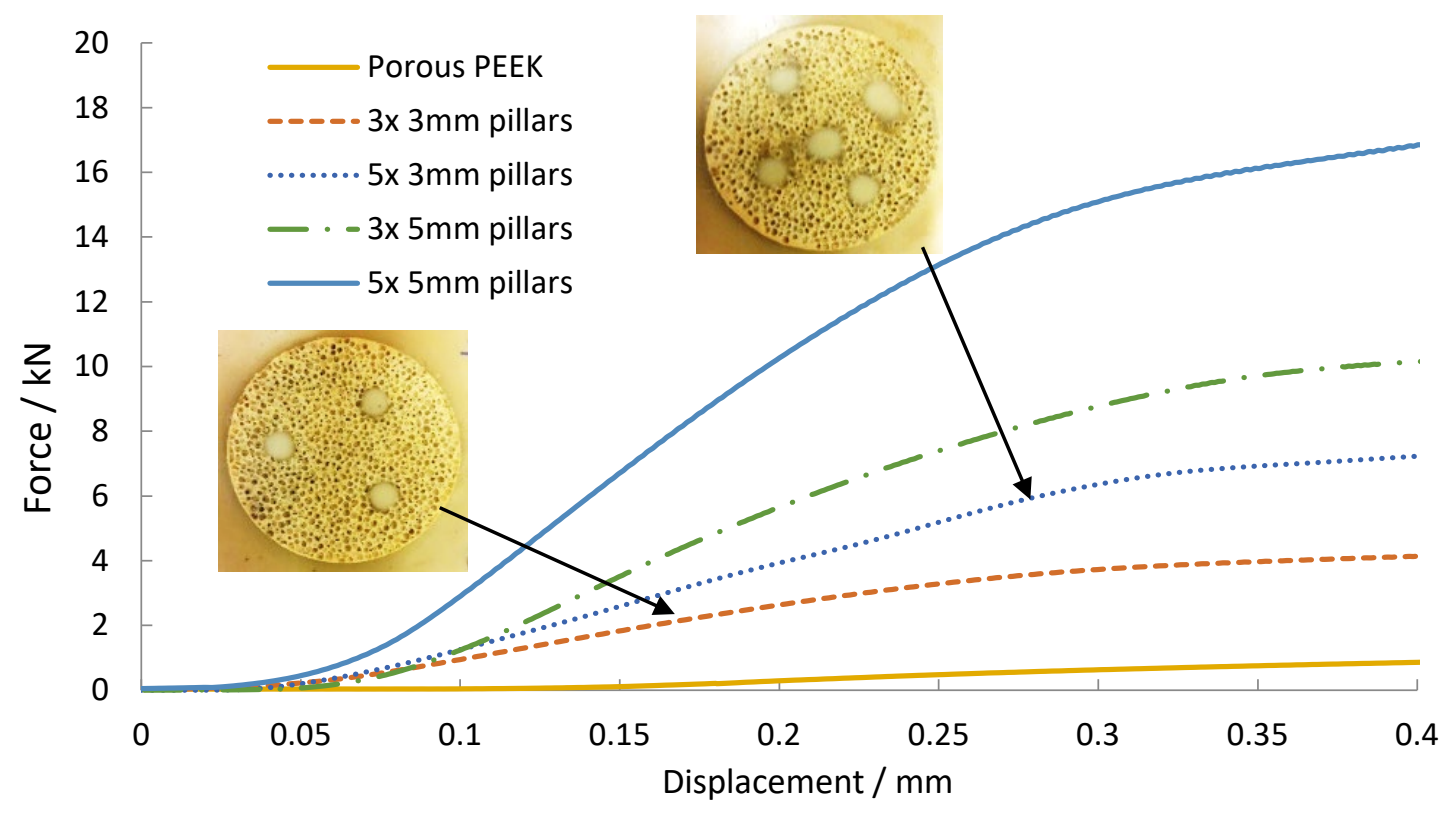

Figure 13 Typical compressive force - displacement curves for porous inserts with and without "pillars".

Table 1 Summary of compressive mechanical properties for porous inserts with and without "pillars"

\begin{tabular}{|l|c|c|}
\hline & Stiffness / MPa & Yield stress / MPa \\
\hline No pillars & $73 \pm 5$ & $2.1 \pm 0.1$ \\
\hline 3x 3 mm pillars & $257 \pm 24(272)$ & $8.4 \pm 0.3(8.9)$ \\
\hline 5x 3 mm pillars & $386 \pm 35(407)$ & $13.0 \pm 0.4(13.4)$ \\
\hline 3x 5 mm pillars & $614 \pm 28(632)$ & $21.1 \pm 0.6(21.1)$ \\
\hline 5x 5 mm pillars & $990 \pm 42(1006)$ & $30.3 \pm 0.6(33.7)$ \\
\hline
\end{tabular}




\subsection{Conclusions}

A simple and adaptable process for the production of porous PEEK has been demonstrated, involving the infiltration of a packed bed of salt beads, facilitated by compression moulding. The process has the capacity to vary the pore size and porosity within the range suitable for materials to replace bone and to produce large, thin parts. The properties of the resulting parts were shown to be improvements on those made by a process that melts compacted PEEK powder (without pressure), but is below the lower level of stiffness and strength required to match trabecular bone.

A simple process to injection over-mould PEEK-salt inserts, made by compression moulding, that contain drilled holes and surface porosity, was demonstrated. The creation of surface porosity was paramount in the attainment of good bonding between the moulding and the insert. The inserts were designed in such a way that strengthening "pillars", created by flow of injection moulded polymer through the drilled holes, support the compressive load, protecting the porous structure around them. It was found that the mechanical performance was dictated by the cross sectional area of these pillars and that as little as $35 \mathrm{~mm}^{2}$ of support was required to achieve properties exceeding the lower limits for trabecular bone.

Acknowledgements: AS would like to thank the Directorate General Higher Education of Indonesia (DGHE / DIKTI ) and UIN Sultan Syarif Kasyim Riau for PhD funding. The authors would like to acknowledge financial support, useful discussions and the supply of materials (PEEK) from Invibio Ltd. 


\section{References}

1. Jarman-Smith, M., M. Brady, S.M. Kurtz, N.M. Cordaro, and W.R. Walsh, Chapter 12 - Porosity in Polyetheretherketone, in PEEK Biomaterials Handbook. 2012, William Andrew Publishing: Oxford. p. 181-199.

2. Schmidt, M., D. Pohle, and T. Rechtenwald, Selective Laser Sintering of PEEK. CIRP Annals - Manufacturing Technology, 2007. 56(1): p. 205-208.

3. Kurtz, S.M., ed. PEEK biomaterial handbooks. 2012, Elsevier.

4. Kurtz, S.M. and J.N. Devine, PEEK biomaterials in trauma, orthopaedic, and spinal implants. Biomaterials, 2007. 28(32): p. 4845-4869.

5. Jaekel, D.J., D.W. MacDonald, and S.M. Kurtz, Characterization of PEEK biomaterials using the small punch test. Journal of the Mechanical Behavior of Biomedical Materials, 2011. 4(7): p. 1275-1282.

6. Kurtz, S.M., Chapter 6 - Chemical and Radiation Stability of PEEK, in PEEK Biomaterials Handbook. 2012, William Andrew Publishing: Oxford. p. 75-79.

7. Converse, G.L., T.L. Conrad, C.H. Merrill, and R.K. Roeder, Hydroxyapatite whiskerreinforced polyetherketoneketone bone ingrowth scaffolds. Acta Biomaterialia, 2010. 6(3): p. 856-863.

8. Moskalewicz, T., S. Seuss, and A.R. Boccaccini, Microstructure and properties of composite polyetheretherketone/Bioglass ${ }^{\circledR}$ coatings deposited on $\mathrm{Ti}-6 \mathrm{Al}-7 \mathrm{Nb}$ alloy for medical applications. Applied Surface Science, 2013. 273(0): p. 62-67.

9. Md. Nizam Uddin, Puttagounder S. Dhanasekaran, Ramazan Asmatulu, Mechanical properties of highly porous PEEK bionanocomposites incorporated with carbon and hydroxyapatite nanoparticles for scaffold applications, Progress in Biomaterials (2019) 8:211-221.

10. Bose S, Roy M, Bandyopadhyay A (2012) Recent advances in bone tissue engineering scaffolds. Trends Biotechnol 30(10):546-554

11. Saiz E, Zimmermann EA, Lee JS, Wegst UG, Tomsia AP (2013) Perspectives on the role of nanotechnology in bone tissue engineering. Dental Mater 29(1):103-115

12. Morgan E F, Keaveny T M. Dependence of yield strain of human trabecular bone on anatomic site. J. Biomech. 2001;34:569-577 
13. Hildebrand T, Laib A, Muller R, et al. Direct three-dimensional morphometric analysis of human cancellous bone: microstructural data from spine, femur, iliac crest, and calcaneus. J Bone Miner Res. 1999;14:1167-1174.

14. Gladius Lewis. Properties of open-cell porous metals and alloys for orthopaedic applications. J Mater Sci: Mater Med (2013) 24: 2293-2325.

15. E.M.Prieto, S.A.Guelcher, Tailoring properties of polymeric biomedical foams, in Biomedical Foams for Tissue Engineering Applications, Woodhead Publishing, 2014, Pages 129-162.

16. G.Chen, N.Kawazoe, Preparation of polymer-based porous scaffolds for tissue engineering, in Characterisation and Design of Tissue Scaffolds, 2016, Pages 105-125, Woodhead Publishing Series in Biomaterials.

17. Siddiq, A.R., Kennedy, A.R. Porous poly-ether ether ketone (PEEK) manufactured by a novel powder route using near-spherical salt bead porogens: Characterisation and mechanical properties, 2015, Materials Science and Engineering C47,180-188

18. Hou, Q., D.W. Grijpma, and J. Feijen, Porous polymeric structures for tissue engineering prepared by a coagulation, compression moulding and salt leaching technique. Biomaterials, 2003. 24(11): p. 1937-1947.

19. Reignier, J. and M.A. Huneault, Preparation of interconnected poly( $\varepsilon$-caprolactone) porous scaffolds by a combination of polymer and salt particulate leaching. Polymer, 2006. 47(13): p. 4703-4717.

20. Cannillo, V., F. Chiellini, P. Fabbri, and A. Sola, Production of Bioglass ${ }^{\circledR} 45$ S5 Polycaprolactone composite scaffolds via salt-leaching. Composite Structures, 2010. 92(8): p. 1823-1832.

21. Heijkants, R.G.J.C., T.G. Tienen, J.H. Groot, A.J. Pennings, P. Buma, R.P.H. Veth, and A.J. Schouten, Preparation of a polyurethane scaffold for tissue engineering made by a combination of salt leaching and freeze-drying of dioxane. Journal of Materials Science, 2006. 41(8): p. 2423-2428.

22. El-Kady, A.M., R.A. Rizk, B.M. Abd El-Hady, M.W. Shafaa, and M.M. Ahmed, Characterization, and antibacterial properties of novel silver releasing nanocomposite scaffolds fabricated by the gas foaming/salt-leaching technique. Journal of Genetic Engineering and Biotechnology, 2012. 10(2): p. 229-238.

23. Kim, T.G., H.J. Chung, and T.G. Park, Macroporous and nanofibrous hyaluronic acid/collagen hybrid scaffold fabricated by concurrent electrospinning and deposition/leaching of salt particles. Acta Biomaterialia, 2008. 4(6): p. 1611-1619. 
24. Flaibani, M. and N. Elvassore, Gas anti-solvent precipitation assisted salt leaching for generation of micro- and nano-porous wall in bio-polymeric 3D scaffolds. Materials Science and Engineering: C, 2012. 32(6): p. 1632-1639.

25. Cai, Q., J. Yang, J. Bei, and S. Wang, A novel porous cells scaffold made of polylactide-dextran blend by combining phase-separation and particle-leaching techniques. Biomaterials, 2002. 23(23): p. 4483-4492.

26. A. Jinnapat, A.R. Kennedy. The manufacture of spherical salt beads and their use as dissolvable templates for the production of cellular solids via a powder metallurgy route. Journal of Alloys and Compounds 499 (2010) 43-47

27. Jinnapat, A.; Kennedy, A. The Manufacture and Characterisation of Aluminium Foams Made by Investment Casting Using Dissolvable Spherical Sodium Chloride Bead Preforms. Metals 2011, 1, 49-64.

28. Jinnapat, A.; Kennedy, A. Characterisation and Mechanical Testing of Open Cell Al Foams Manufactured by Molten Metal Infiltration of Porous Salt Bead Preforms: Effect of Bead Size. Metals 2012, 2, 122-135

29. Schultz AB, Andersson GBJ. Analysis of Loads on the Lumbar Spine. Spine (Phila Pa 1976) $1981 ; 6: 76-82$.

30. Nachemson A. Lumbar Intradiscal Pressure: Experimental Studies on Post-Mortem Material. Acta Orthop. Scand. 1960;31:1-104.

31. Douglas G. Orndorff, M.A.S., Katie A. Patty, Force Transfer in the Spine. Journal of The Spinal Research Foundation, 2012. 7(2): p. 30-35.

32. Jensen, G.M., Biomechanics of the Lumbar Intervertebral Disk: A Review. 1980. 60: p. 765- 773 .

33. A.R.Siddiq, A.R.Kennedy A novel method for the manufacture of porous structures with multi-component, coated pores, Materials Letters, Volume 196, 1 June 2017, Pages 324-327.

34. Xiao, Z, Harper, LT, Kennedy, AR \& Warrior, NA 2017, 'A water-soluble core material for manufacturing hollow composite sections' Composite Structures, vol 182, pp. 380-390.

35. Langston, P., Kennedy, A.R. Discrete element modelling of the packing of spheres and its application to the structure of porous metals made by infiltration of packed beds of $\mathrm{NaCl}$ beads,2014, Powder Technology,268,210-218

36. Mortensen, A. (2000). Melt Infiltration of Metal Matrix Composites. Compr Compos Mater. 3. pp. 521-554 
37. Otaru, A.J.; Kennedy, A.R., Investigation of the Pressure Drop Across Packed Beds of Spherical Beads : Comparison of Empirical Models With Pore-Level Computational Fluid Dynamics Simulations, Journal of Fluids Engineering, Vol. 141, No. 7, 071305, 08.04.2019

38. Otaru, AJ, Morvan, HP \& Kennedy, AR 2018, 'Measurement and simulation of pressure drop across replicated porous aluminium in the Darcy-Forchheimer regime' Acta Materialia, vol 149, pp. 265-273.

39. Jia, J., Siddiq, A.R., Kennedy, A.R. Porous titanium manufactured by a novel powder tapping method using spherical salt bead space holders: Characterisation and mechanical properties, 2015, Journal of the Mechanical Behavior of Biomedical Materials,48,229-240

40. Andrews, E.W., Gioux, G., Onck, P., Gibson, L.J., 2001. Size effects in ductile cellular solids. Part II: experimental results. Int. J. Mech. Sci. 43, 701-713.

41. Torstrick FB, Evans NT, Stevens HY, et al. Do Surface Porosity and Pore Size Influence Mechanical Properties and Cellular Response to PEEK? Clin. Orthop. Relat. R. 2016; 474:2373-2383.

42. Evans NT, Irvin CW, Safranski DL, et al. Impact of surface porosity and topography on the mechanical behavior of high strength biomedical polymers. J Mech Behav Biomed. 2016;59:459-473.

43. Evans NT, Torstrick FB, Safranski DL, et al. Local deformation behavior of surface porous polyether-ether-ketone. J Mech Behav Biomed. 2017;65:522-532.

44. PEEK data, https://www.victrex.com/en/datasheets, accessed 11/5/2020

45. M. F. Ashby, A.G.Evans., N. A. Fleck, L. J. Gibson, J. W. Hutchinson, and H. N. G. Wadley, Metal Foams: A Design Guide. 2000, Boston, Mass, USA: Butterworth Heinemann. 